\section{Genes for the Common Man}

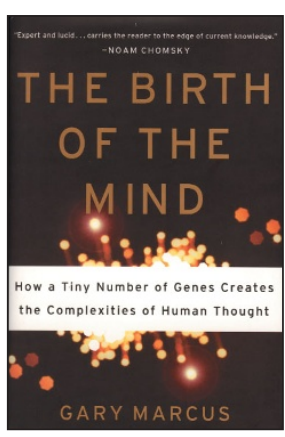

\section{The Birth of the Mind}

By Gary Marcus

Basic Books, 2003

240 pp. hardcover, $\$ 26.00$

ISBN 0-4650-4405-0

\section{Reviewed by Leonard K Kaczmarek}

Genetics must be in the air. In last year's Pulitzer Prize-winning novel Middlesex, by Jeffrey Eugenides, the hermaphrodite protagonist Cal laments that his psychological makeup cannot be explained by the fact that he is genetically male with a mutant gene, or by the fact that he was brought up as a girl. His environment is not sufficient to explain his behavior, and the genetic code "underlying our being is woefully inadequate. Instead of the expected 200,000 genes, we have only 30,000 . Not many more than a mouse."

It is exactly this conundrum that Gary Marcus attempts to explain in The Birth of the Mind. A cross between a textbook and a cheerleading rally in support of the way genes work, this text covers the spectrum from the structure of DNA, to egg-laying behavior in the sea hare Aplysia, to computer modeling of neuronal networks and theories of how babies acquire language. To keep us entertained during this whirlwind tour, characters such as Woody Allen, the comedian Ali G, and Princess Leia and other participants in the Star Wars saga keep popping up in its pages. Paul McCartney, Henry Kissinger and Meryl Streep also make cameo appearances.

The average reader of this book will not be looking for (nor will they get) a deep understanding of the topics presented, but will instead get a taste of many areas. It has an engaging style and is easy to read. Marcus does a fine job of explaining that the current estimate of the number of genes encoding proteins (about 30,000) greatly underestimates the complexity of the genome. For example, the single gene encoding the Slo potassium channel, an important regulator of neuronal excitability, may produce millions of different channels, each with distinct biochemical or electrical properties.

The plot of this book is the familiar battle between nature and nurture. On either side of the battlefield, Marcus marshals experiments that he interprets as favoring each camp: the 'nativist' view that the brain and its associated mental processes are largely predetermined, or the opposing view that the mind is a blank slate before experience modifies it. Nevertheless, in order to keep the plot inter-

Leonard K. Kaczmarek is in the Department of Pharmacology, Yale University School of Medicine, New Haven, Connecticut 06520, USA.

e-mail: Leonard.Kaczmarek@yale.edu esting and varied, he sometimes combines elements without using rigorous logic. For example, to support the notion that normal brain development does not require sensory experience, he cites experiments showing that brain structures develop in the embryos of mutant mice lacking synaptic transmission. This is an interesting and important area, and makes for good reading, but it would be absurd to claim that the discovery favors the idea that experience is not important for normal mental development. Moreover, he fails to mention that this study also found that neurons without synaptic transmission eventually die because they are unable to communicate with their neighbors, a wonderful piece of ammunition for the other side.

This book is not for scientists. To make an overview of so many fields clearly requires oversimplification. At an early point, Marcus states that gray matter of the brain is "most likely to stay constant regardless of experience," whereas "white matter...consists of modifiable neural connections that might be expected to be most influenced by experience." Neurobiologists are likely to cringe at such assertions. The urge to keep the focus on genes at all costs renders some of the conclusions forced or trivial. Marcus states, "it is no exaggeration to say that genes are essential to nearly every aspect of memory, and the process of learning; without them learning itself would not exist." Of course it would not exist-neither would the liver, earlobes or cucumbers.

At other times, the attempt to keep the focus on genes while discussing learning and memory is actually misleading. The text shifts back and forth between the idea that genes are important simply because they encode proteins - which are of course required for everything - and the idea that changes in gene expression reflect experience. We know that learning a simple task or recalling a phone number can occur in a few seconds, a time far too short to require changes in gene transcription. Yet a naive reader could be confused into thinking that all learning requires changes in gene transcription. In fact, the author comes very close to saying so: "The reason animals can learn is that they can alter their nervous system on the basis of external experience. And the reason that they can do that is that experience itself can modify the expression of genes [author's emphasis]." In his discussion of how neuronal stimulation leads to long-term potentiation of synaptic responses, he ignores early stages of the process that occur independent of gene transcription. In a textbook or a scholarly work, these quirks would be fatal flaws.

It will come as no surprise to anyone reading this journal that, in the end, the winner of the battle between innateness and flexibility is "not one or the other, but both." In many ways, however, the final chapter is the best. The author provides a lucid essay on future trends related to genetic manipulation and screening for patterns that might lead to specific types of behavior. The book ends with the statement that, with a better understanding of the role of specific genes, we can begin to use the knowledge to make the most of nurture. Although we have an emerging understanding of these issues at the biological level, we are still far from knowing how they will be applied in real life. Until we know better, the protagonist of Middlesex, like the rest of us, will have to fend for himself. 